\title{
Molecular detection and characterization of sustainable intracellular contaminants in commercially used cell cultures for pre-clinical studies
}

\author{
Charles NTUNGWEN FOKUNANG ${ }^{1,4^{*}}$, Estella Achick TEMBE-FOKUNANG ${ }^{1}$, \\ Salwa BARKWAN ${ }^{2}$, Joseph FOKAM ${ }^{1}$, Luc GWUM ${ }^{1}$, Frederick Aghem KECHIA ${ }^{6}$, \\ Bethelemy NGAMENI ${ }^{3}$, Donatien GATSING ${ }^{5}$ and Paul TOMKINS ${ }^{3}$ \\ ${ }^{I}$ Department of Toxicology and Pharmacology, Faculty of Medicine and Biomedical Sciences, \\ University of Yaoundé 1, Cameroon. \\ ${ }^{3}$ Centre for Biopolymer and Bio-Molecular Research, Athlone College of Technology, Republic of Ireland. \\ ${ }^{2}$ Department of Pharmacognosy and Medicinal Chemistry, Faculty of Medicine and Biomedical Sciences, \\ University of Yaoundé 1, Cameroon. \\ ${ }^{4}$ Department of Biological Sciences, Faculty of Science, University of Bamenda, Cameroon. \\ ${ }^{5}$ Département de Biochimie, Faculté des Sciences, Université de Dschang, Cameroun. \\ ${ }^{6}$ Department of Biomedical Sciences, Faculty of Health Sciences, University of Bamenda, Cameroon. \\ *Corresponding author; E-mail: charlesfokunang@yahoo.co.uk; Tel: (+237)670902446, +237694218670
}

\begin{abstract}
Microbial contamination in cell and tissue culture is a constant problem, which can compromise development and applications of cell lines. An immediate consequence of cell culture contamination is loss of researcher time, money and effort spent developing cultures and setting up experiments. There are adverse effects detected on cultures suffering from undetected biological contamination. This hidden contamination can potentially achieve high densities altering the growth and characteristics of the cultures. The objective of this study was to assess the molecular detection and characterization of sustainable intracellular contaminants in commercially used cell cultures use for regulatory pre-clinical studies for developing new chemical entities. This study was prompted by a series of observations by multiple researchers that cell lines were harbouring visible black particulate contaminants, capable of intracellular mobility with secondary impacts on cell adherence and lyses. This was initially limited to human liver cells, $\mathrm{HepG} 2, \mathrm{C} 3 \mathrm{~A}$ and $\mathrm{CaCO}_{2}$ cell lines, but recently similar evidence has been found in a series of other cell lines as well. Giemsa staining did show many spore-like entities in the cytoplasm mainly of $0.5-1 \mu$ diameter, rounded and transparent in colour. Electron microscope examination of $\mathrm{C} 3 \mathrm{~A}$ infected cell line revealed the presence of numerous intracellular bacteria located in vacuoles or free in the host cytoplasm. In addition, the interaction of this bacterium with epithelial cells was associated with the elongation of micro-villar extension that extruded from the host cell membranes and engulfed the bacteria. This internalization mechanism strongly resembles Salmonella- or Shigella-induced macro-pinocytosis. The strain was characterized using the 16S RNA sequence that amplified the gene from many genera. The closest phylogenetic relative was $\mid \mathrm{HQ877772.1|}$ Escherichia sp. A94 with 88\% 16S ribosomal RNA gene sequence similarity. It was proposed that unidentified strain be assigned as type strain of species of the bacteria origin based on the 16S rRNA gene sequence search in Ribosomal Database project, small subunit rRNA and large subunit rRNA database together with the phylogenetic tree analysis.
\end{abstract}

(C) 2017 International Formulae Group. All rights reserved.

Keywords: Intracellular contaminants, cell cultures, bacteria culture, pre-clinical studies. 


\section{INTRODUCTION}

Microbial contamination in cell and tissue culture is a constant problem, which can compromise development and applications of cell lines. An immediate consequence of cell culture contamination is loss of researchers' time, money and effort spent developing cultures and setting up experiments (Kim, 2007; Fogh et al., 2015) Apart from mycoplasma, microbial contamination of cell cultures is usually very detectable and largely concerns media and can be addressed by sanitation procedures. Mammalian cells can host microbes in addition to mycoplasma, in a form that preserves cell survival but seriously damages their expressive behaviour and function is a major concern (Zenk and Hansel, 2009; Everoad et al., 2012). There are adverse effects on cultures suffering from undetected biological contamination. This hidden contamination can potentially achieve high densities altering the growth and characteristics of the cultures (Croxton et al., 2012; Usta et al., 2014).

Tissue culture or cell culture are terms used interchangeably for the process where cells are grown and maintained in a controlled environment such as a laboratory, outside their natural and original source (Gupta et al., 2014). Cell culture is a vital technique in many branches of biological research, from cancer research to vaccine development and therefore a cell culture contaminant can be defined as some element in the culture system that is undesirable because of its possible adverse effects on either the system or its use (Ajibola et al., 2017). 'Contamination cannot be totally eliminated, but it can be managed to reduce both its frequency of occurrence and the seriousness of its consequences' (Ryan, 2005; Borman et al., 2013).

The presence of microbial contamination- bacterial, fungi, mycoplasma, or protozoa- in cell culture seriously compromises virtually all research or production work involving culture technology (Behrendorff et al., 2013). Although many contamination events are overt and readily apparent, others are insidious and more difficult to detect (Ikonomi, 2006; Ecology 2011). There are many types of contaminants, but all result in cell death and poor culture which cost the laboratory both time and money.

Improvements have been made in conventional culture methodologies, where there have been numerous studies analyzing the use of nucleic acid test for the detection of positive bacterial contamination (Marlowe, 2003; Thomas et al., 2013). Molecular biological methods for detection of nucleic acids have shown to be greater sensitivity than immunological and staining methods (Everoad et al., 2012; Mohammad et al., 2015). Molecular detection methods allows for detection of non-cultural bacteria (Lleo and Canepari, 2005). PCR assays provide fast, dependable and cost-effective methods for quality assessment, ultimately resulting in faster product release and product optimization (Jimenez, 2001; Evaroad et al., 2012). Sequence based molecular technique have been used to characterize bacteria, using 16S rRNA sequence as a common tool for detection of contamination in groundwater and industrial water systems (Grahn et al., 2003; Hay, 2010). Studies by Jamenez et al., (2007), used the highly conserved bacterial ribosomal DNA sequence in PCR-based assay to determine sterility of pharmaceutical samples, The group also reported that conserved eubacterial sequences has been used in clinical and industrial samples for PCR analysis. The study by Nocker (2008), described nucleic acids amplification as a significant improvement in technology for microbial research laboratories and microbial diagnostic industries, due to its utility to be automated.

Scientists must maintain careful aseptic technique and adhere to proper clean and sterile procedures while manipulating cells in order to keep them alive and healthy. Research take multiple steps, including 
aseptic culture handling, filter sterilization, purchasing of liquid media and solutions, and inclusion, and inclusion of antibiotics in the growth media, to keep the cultures free of unwanted organism (Degelling et al., 2012; Blazkova et al., 2015). An additional complication arise when researchers use lines that are not commercially available and are often irreplaceable, difficult to obtain, or need re-derivation from primary cells (Jennifer et al., 2010; Jerome et al., 2014). In case of noncommercially available lines, all attempts are usually taken to clean up the culture by selectively killing the contamination without harming the cell line. Often the culprit of culture contamination is mycoplasma, intracellular and bacteria that can be almost undetectable in culture. Approximately 20\% of 460 human cell lines surveyed contained mycoplasma (Uphoff and Horn, 2011; Kly, 2013). Numerous commercial kits are available to identify mycoplasma contamination (Garner and Charkraborti, 2000; Fogh et al., 2015) and antibiotic solutions are commercially available to rid cultures of them. Unknown bacterial contamination can be transient, and contamination is common with poor aseptic technique and can be devastating in a research setting (Croxton et al., 2012). In the laboratory contaminants can come from different sources and in some cases from the laboratory coats of researchers, medical personal poor hygiene work conditions, and non-labeling of materials on work surfaces (Zenk and Hansel, 2009; Awodiran et al., 2014).

While many undesirable organisms may steal nutrients from cells lines in cultures, they may also prey on the cells themselves. Predatory bacterial have been shown to feed on other bacteria (Klausegger et al., 2010; Kly, 2013), particularly in a limited nutrient environment (Nocker, 2008; Vimlesh et al., 2009). Experimental results may also be altered due to unwanted activation of cells. Different cellular functions, including those triggered by Tool-like receptors, can be activated by variety of bacterial components
(Testro, 2009; Zenk and Hansel, 2009; Blazkova et al., 2015).

The highly biologically reactive molecules have major influences in vivo on humoral and cellular systems. Studies of endotoxins using in vitro systems have shown that they may affect the growth or performance of cultures and are a significant source of experimental variability (Case Gould, 1984; Ryan, 2005; Weids, 2007). Furthermore, since the use of cell culture produced therapeutics, such as hybridomas and vaccines, are compromised by high endotoxin levels, efforts must be made to keep endotoxin levels in culture systems as low as possible. Biological contamination can be subdivided into two groups based on the difficulty of detecting them in culture. The first concern those that are easy to detect such as bacteria, molds and yeast and secondly those as that are more difficult to detect, and as a result potentially more series culture problems, such as viruses, protozoa, mycoplasmas and other cell lines (Fogh ,1971; Incorporated, 2002).

The objective of this study was to assess the molecular detection and characterization of sustainable intracellular contaminants in commercially used cell cultures use for regulatory pre-clinical studies for developing new chemical entities.

\section{MATERIALS AND METHODS}

This was a prospective analytic cross sectional study, conducted at the centre for Bio-molecular and Biopolymer laboratory, at the Athlone Institute of Technology., Republic of Ireland

\section{In vitro culture}

C3A cells were cultured in Dulbecco's modified Essential medium (DMEM) with the addition of $10 \%$ bovine serum (FBS).

\section{Cells Lysate preparation}

The medium for contaminated cells were removed and the cells washed with PBS buffer. Trypsin was used to detach cells from the flask, and cells were collected in universal 
tube for centrifugation. The cells were plated and were exposed to the freeze and thaw process using liquid nitrogen at $60{ }^{\circ} \mathrm{C}$. The DNA isolation Kit from Sigma Aldrich was used for the isolation of DNA.

\section{DNA Extraction}

The cell pellets were obtained by centrifugation and the concentrated samples were suspended in a $500 \mu \mathrm{l}$ of TE buffer( 10 $\mathrm{mM}$ Tris-HCL, $1 \mathrm{mM}$ EDTA, $\mathrm{pH}$ 7.5) .The efficiency of the DNA extraction and purification protocol was tested by including in each series of experiments and before DNA extraction, a control consisting of distilled deionized water sample was added. The DNA concentration was determined by Picodrop (Testro, 2009).

\section{DNA amplification}

DNA was quantified using Picodrop, $59 \mathrm{ng}$ of DNA was added to a $50 \mu \mathrm{l}$ of PCR reaction using Bioline Kit. The primers of $16 \mathrm{~s}$ gene listed in Table 1.

The reaction were run using the following cycling parapeters: $95{ }^{\circ} \mathrm{C}$ for $4 \mathrm{~min}$, 30 cycles of 30 second at $95{ }^{\circ} \mathrm{C}, 30$ second at $55{ }^{\circ} \mathrm{C}$ and $45 \mathrm{sec}$ at $72{ }^{\circ} \mathrm{C}$, with final elongation step of $10 \mathrm{~min}$ at $72{ }^{\circ} \mathrm{C}$ before a 4 ${ }^{\circ} \mathrm{C}$ hold. (RoboCycler ${ }^{\circledR}$ Gradient 96, Stratagene: Cambridge). A $10 \mu \mathrm{l}$ of the reaction mixture were visualized on $1 \%$ TEA agarose with ethidium bromide at $8 \mathrm{~V} / \mathrm{cm}$ and the reaction product was visualized under Gel doc/UV trans-illuminator (Syngene). The PCR product was purified by Qiagen gel extraction kit using the following protocol described below. The DNA fragment was excised from the agarose gel with a clean sharp scalpel. Then the gel slice was weighed in an eppendorf. A 3 volumes of buffer QG was then added to 1 volume of gel $(100 \mathrm{mg}$ $100 \mu \mathrm{l})$. The mixture was then incubated at $50^{\circ} \mathrm{C}$ for 10 minutes. The gel was dissolved by vortexing the tube every $2-3$ mins during the incubation until the mixture colour was uniformly yellow. A 1 gel volume of Iso- propanol was then added to the sample and mixed. A QIAquick spin column was then placed in a $2 \mathrm{ml}$ collection tube provided. The sample was applied to the QIAquick column followed by centrifugation for one minute to bind the DNA to the column. The flowthrough was discarded and the QIAquick column was placed back in the collection tube. This was followed by adding $0.75 \mathrm{ml}$ of buffer PE to QIAquick column and centrifuged for 1 minute to wash. The flowthrough was again discarded and the QIAquick column centrifuged for an additional 1 minute at $10,000 \times g$. The QIAquick column was then placed into a clean $1.5 \mathrm{ml}$ eppendorf. A $50 \mu \mathrm{l}$ of buffer EB (10mM Tris- $\mathrm{Cl}, \mathrm{pH} 8.5$ ) was added to the centre of the QIAquick membrane and the column centrifuged for $1 \mathrm{~min}$ to elute the DNA.

After quantitation of the PCR product, with Picodrop, DNA (all samples amount were around $60 \mathrm{ng}$ ) and was submitted for sequencing at the Bioscience Ltd, St. James Hospital, Dublin, Ireland, along with 100 pmoles primers. For the two sequences, one originated from the first primer (universal general), and the other one from the second Primers (U16S-staph). The two sequences were aligned using NCBI's BLAST. Sequences of around 450 base pairs were obtained for each of the two samples.

The rRNA based analysis is a central method in microbiology used not only to explore microbial diversity but also to identify new strains. A Sigma Aldrich kit for genome extraction (Gen Elute Bacterial Genomic DNA Kit) was used to ensure the isolation of the microbe genome. To process the freeze and thaw the liquid nitrogen was used and a bath at $60{ }^{\circ} \mathrm{C}$ was used to lyse the spore like microbe. The PCR produced different bands compared to the single band of positive control of Staphylococcus aureus genomeand the different bands wer compared with the single band of positive control of Staphylococcus aureus. 
Table 1: Universal primers used in PCR reactions to amplify the $16 \mathrm{~s}$ region in contaminated cells.

\begin{tabular}{|c|c|c|}
\hline Primer & Forward primer & Reverse primer \\
\hline $\begin{array}{l}\text { Universal- } \\
\text { general }\end{array}$ & $\begin{array}{l}5^{\prime} \\
\text { TGAGCTCAAGCTTCAGCMGTCCGCGGT } \\
\text { AATWC-3' }\end{array}$ & $\begin{array}{l}\text { 5'- } \\
\text { TTTTGGATCCTCTAGAACGGGCGGTGTGT } \\
\text { RC-3 }\end{array}$ \\
\hline $\begin{array}{l}\text { U16S- } \\
\text { staph }\end{array}$ & 5' GGAATTCAAAKGAATTGACGGG-3' & 5' CGGGATCCCAGGCCCGGAACG-3' \\
\hline
\end{tabular}

\section{Giemsa Stain}

Cells were seeded at cell density of $5 \times 10^{3}(\mu \mathrm{l} / \mathrm{ml})$, measured with the aid of a haemocytometer, on cover slips, for $72 \mathrm{~h}$ at 37 ${ }^{\circ} \mathrm{C}$. The cells were cultured without changing medium, and were washed with phosphatebuffered saline (PBS), and fixed with methanol for $10 \mathrm{~min}$ at room temperature. The fixed cells were immersed in a Giemsa solution $(10 \%)$ for $15 \mathrm{~min}$ at room temperature. Staining was followed by rinsing the cover-slips for two to five minutes in phosphate buffer, air-dried, and mounted on microscope slides in DPX (1:1 glycerol: PBS) and then examined under an oil-immersion objective microscope at $1000 \mathrm{x}$ magnification.

\section{Transmission Electron Microscopy (TEM)}

The cross sections of the $\mathrm{C} 3 \mathrm{~A}$ cells were prepared as follows. The cells were fixed with $3 \%$ glutaraldehyde in $0.2 \mathrm{M}$ cacodylate buffer ( $\mathrm{pH} \mathrm{7.4)}$ ) at $4{ }^{\circ} \mathrm{C}$ for $2 \mathrm{~h}$ and then post fixed in $1 \% \mathrm{OsO}_{4}$ in cacodylate buffer at $4{ }^{\circ} \mathrm{C}$ for $1 \mathrm{~h}$. After dehydration in a graded series of ethanol, the cell cultures were embedded in a 2-mm-thick Epon coating, in the tissue culture well and polymerized for 3 days at $60{ }^{\circ} \mathrm{C}$. Suitable areas were reoriented either parallel or perpendicular to the cell layer surface on Epon blocks with an Epon mixture. Ultrasections were contrasted with uranyl acetate and lead citrate.

\section{RESULTS}

\section{PCR amplification}

The PCR products ranged in size from 1200 base pair to 500 bp. Five bands were excised and cleaned using a kit (Qiagen,
QiAquick Gel extraction Kit, Ltd). The samples were sent to the Bioscience Company in Dublin for analysis. After sequencing; the resulting sequences were checked for similarity to other known sequences using NCBIs Blast and ribosomal Database project (RDP). As indicated in Figure 1 the PCR amplification as indicated on band lane 1 to 5 showed PCR Bioline ${ }^{\circledR} 100$ bp ladder, line $1 \& 2$, PCR product of sample genome using $16 \mathrm{~S}$ primer giving two product of 450 and 650 bp; line $3 \& 4$ and line 5 using $16 \mathrm{~S}$ primer for bacteria genome gave only one product of $\sim$ 500bp.

\section{PCR amplification of Staphylococcus aureus DNA genome compare to multiple bands in contaminated culture cells sample \\ The gel images in Figure 2 showed four lanes; +ve, S-1, S-2, S-3. The four gel images depicted one band amplified in the positive control of Staphylococcus aureus DNA genome compared to multiple bands contaminated culture cells sample. The Bioline ${ }^{\circledR} 100 \mathrm{bp}$ ladder was used for the PCR amplification. The S-1, S-2 and S-3 gel bands compared to the positive bands showed the presence of contaminants. The base pair for the contaminants were different from the positive.}

Neighbour-joining tree of $16 S$ rRNA PCR product gene sequence homology to the unknown obtained from BIAST search

A phylogenetic tree view of a second PCR product with less homology to genome database indicated that the sequence was unknown as shown in Figure 2, and as 
indicated on the phylogenetic tree analysis. Phylogenetic tree base on the PCR product sequences 16S RNA primers Blastn were searched from NCBI databases. The unknown sequence in this work is highlighted in yellow and the homology Bacteria name are indicated from the NCBI blast search.

A more detailed phylogenetic output indicating the clade for the different homology of bacterial sequences are shown in Figure 3. The unknown bacteria sequence is highlighted in yellow and needed further advance blast search for possible identification for bio-informatics analysis.

We characterized the strain using $16 \mathrm{~S}$ RNA sequence that amplified the gene from many genera. The closest phylogenetic relative was |HQ877772.1|. Escherichia sp. A94 with 88\% 16S ribosomal RNA gene sequence similarity. It was proposed that the unidentified strain be assigned as a typed strain of species of the bacteria origin based on the 16S rRNA gene sequence search in Ribosomal Database project, small subunit rRNA and large subunit rRNA database, together with the phylogenetic tree analysis.
In the different main clades there was the Enterobacter, Salmonella, Escherichia, Enterobactaceae main families.

Transmission electron microscope (TEM) micrograph of $\mathrm{C} 3 \mathrm{~A}$ cells infected with unknown bacteria

The cross section of the cells monolayer as shown in Figure 4 had numerous intracellular bacteria. Micrograph showed membrane ruffling upon contact with bacteria. The bacteria were engulfed by elongated microvilli from infected epithelial cells. High magnification showed partially lysed vacuole membrane containing bacteria, indicating the ability of bacteria to escape from the endocytic vacuoles. The photomicrograph in Figure 4 also clearly showed the presence of numerous bacteria inside the cells. Most of the bacteria observed were enclosed by endocytic vacuoles through Giemsa stain observation. In addition, some bacteria were free in the cytoplasm, perhaps as a result of an escape from endocytic vacuoles by bacterium-induced lyses of the vacuole membrane.

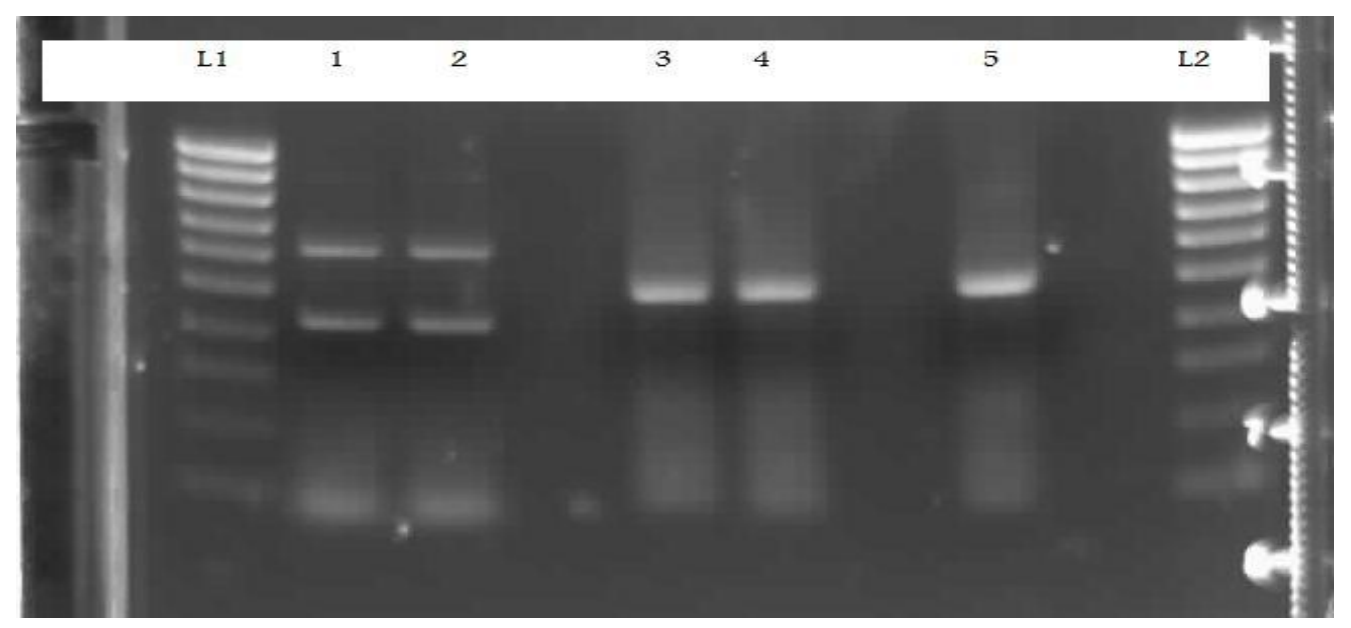

Figure 1: PCR L1 AND L2 Bioline ${ }^{\circledR} 100$ bp ladder, Line 1\&2 PCR product of sample genome using $16 \mathrm{~S}$ primer giving two product of 450 and $650 \mathrm{bp}$; line $3 \& 4$ and 5 using $16 \mathrm{~S}$ primer for bacteria genome giving only one product of $\sim 500 \mathrm{bp}$. 


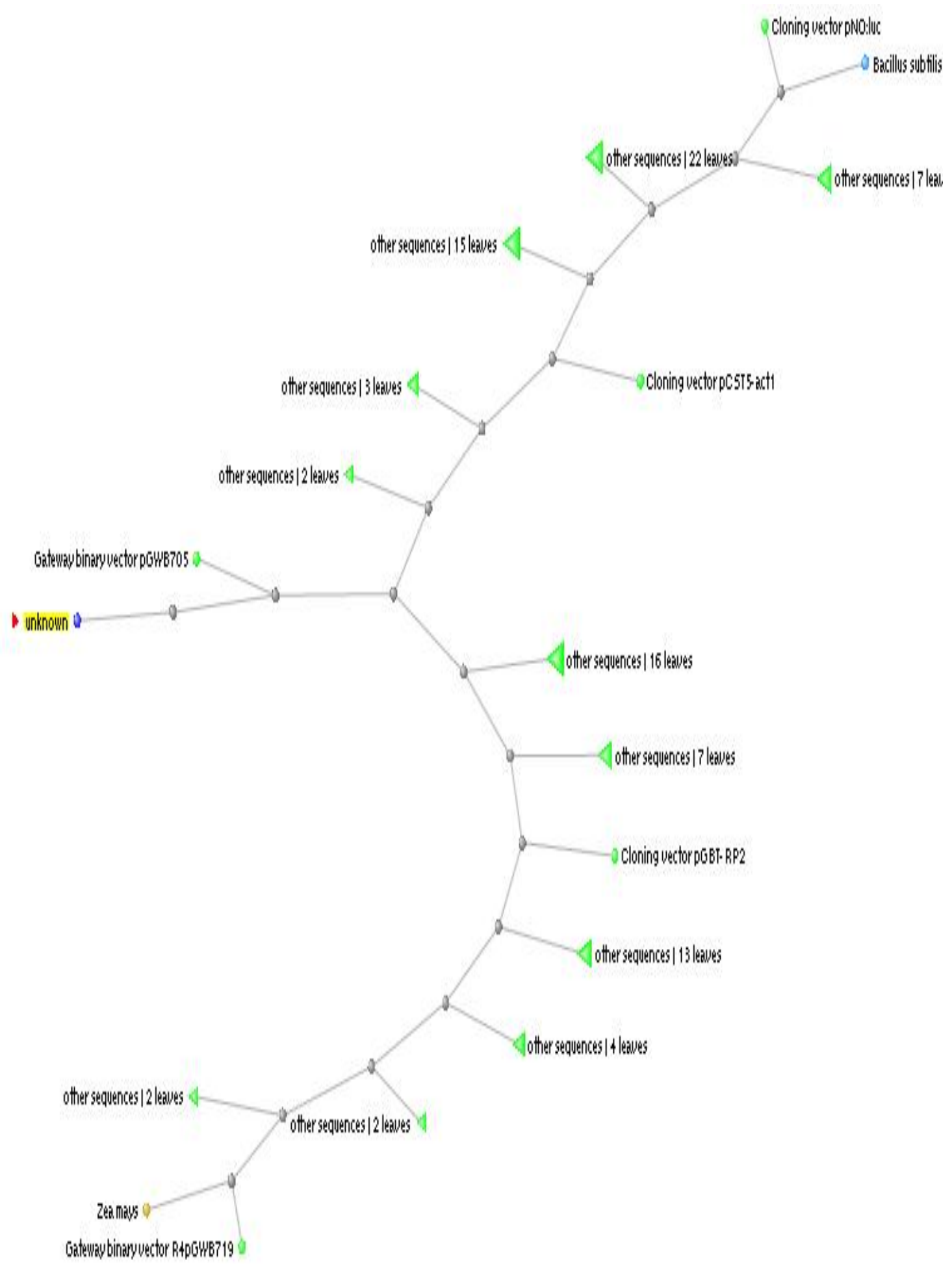

Figure 2: A phylogenetic tree containing all available homology bacterial sequence was constructed from a multiple sequence alignment with the neighbour-joining method using Blast nucleotide search. Scale bar 0.006 changes per site. 


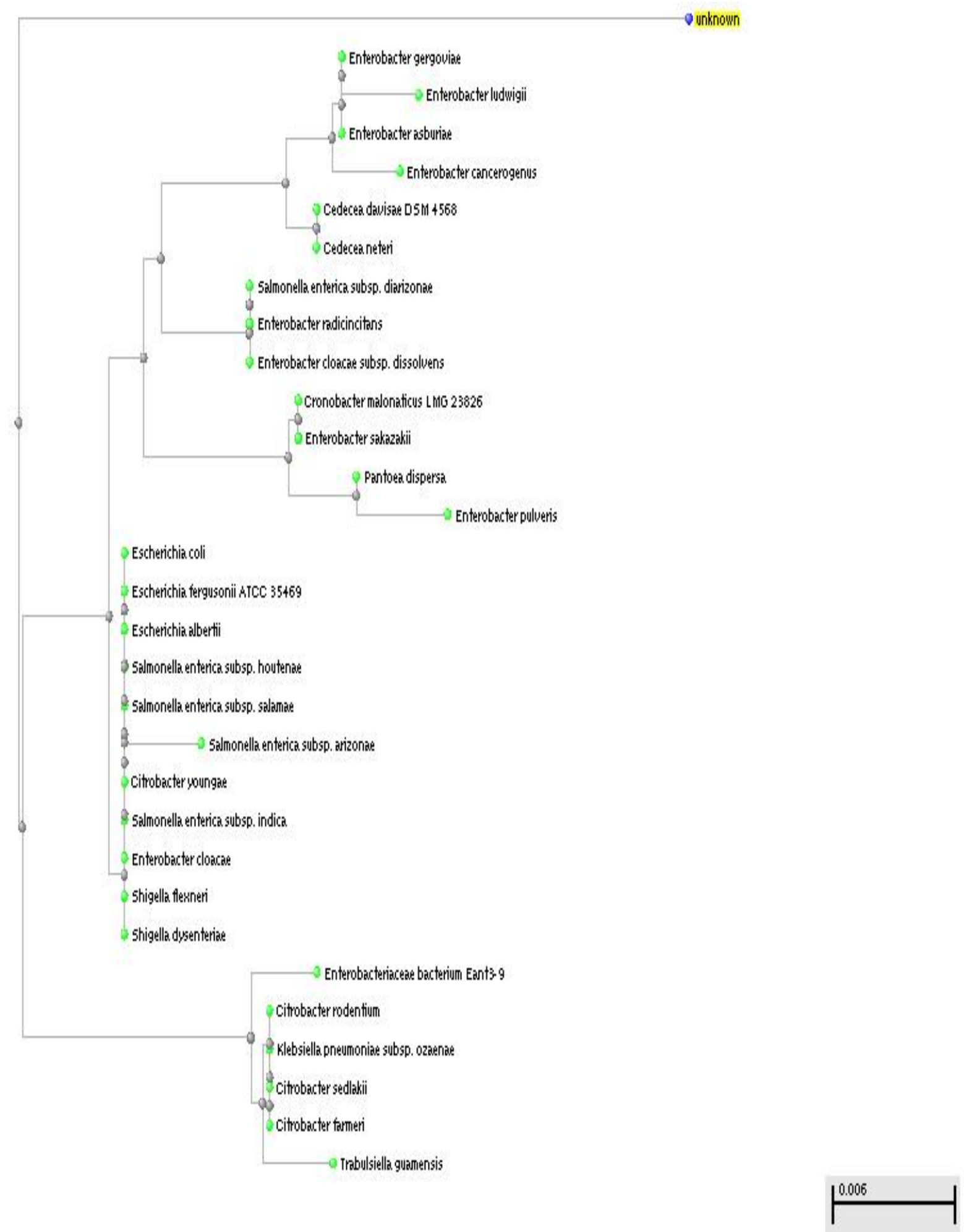

Figure 3: A more detailed phylogenetic output indicating the clade for the different homology of bacterial sequences. 

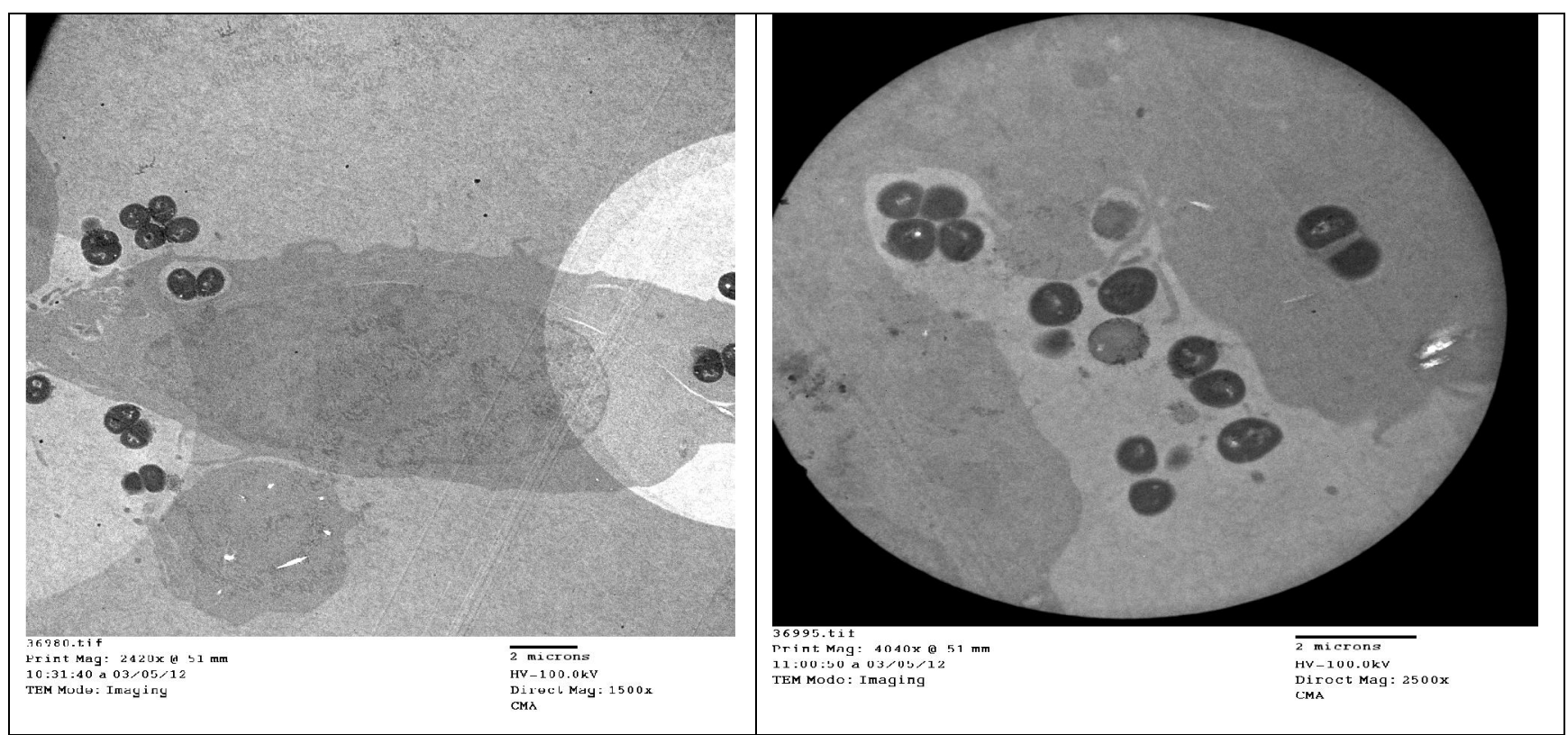

Figure 4: Transmission electron microscope (TEM) micrograph of C3A cells infected with unknown bacteria.

\section{DISCUSSION}

Microbial contamination in cell and tissue culture is a constant problem, which can compromise development and applications of cell lines. An immediate consequence of cell culture contamination is loss of researchers' time, money and effort spent developing cultures and setting up experiments (Fogh et al., 2015) Apart from mycoplasma, microbial contamination of cell cultures is usually very detectable and largely concerns media and can be addressed by sanitation procedures. Mammalian cells can host microbes in addition to mycoplasma, in a form that preserves cell survival but seriously damages their expressive behaviour and function is a major concern. There are adverse effects on cultures suffering from undetected biological contamination. This hidden contamination can potentially achieve high densities altering the growth and characteristics of the cultures (Croxton et al., 2012; Usta et al., 2014; Ajibola et al., 2017). Comparison of PCR product sequence against known sequences of nucleotide database (NCBI) showed that the gene sequence of isolate had variable $88 \%$ $87 \%-95 \%$ sequence similarity (Score $=$ bits, expect $=0.0$ ) with $16 \mathrm{~S}$ rRNA gene sequence of Escherichia coli uncultured bacteria .

The characterized strain using $16 \mathrm{~S}$ RNA sequence amplified the gene from many genera. The closest phylogenetic relative was |HQ877772.1| Escherichia sp. A94 with 88\% $16 \mathrm{~S}$ ribosomal RNA gene sequence similarity. It is proposed that unidentified strain be assigned as type strain of species of the bacteria origin based on the 16S rRNA gene sequence search in Ribosomal Database project, small subunit rRNA and large subunit rRNA database together with the phylogenetic tree analysis. Thus, the data showed that the isolate was a member of the genus Escherichia. Similarity rank program classifier (Ecology, 2011) available at ribosomal database project (Wang et al., 2007) classified the fragment (sample) as a novel genome species of genus with confidence threshold of $95 \%$. 
Most sequence shared 100 identities with Homo sapiens isolate Li110 control region, partial sequence; mitochondrial 100\%, while the rest of the 2 sequences showed highest homology to sequences identity to (88\% gb|HQ877772.1| such as the Escherichia sp, A94 16S ribosomal RNA gene, partial sequence, 88\% dbj|AB609044.1| Escherichia coli gene for 16S rRNA, partial sequence, strain: SI-7, gb|HQ759847.1|, the uncultured organism clone ELU0045-T454-SNIPCRAMgANb_000132 small subunit ribosomal RNA gene, gb|HQ796635.1|.Lastly, the uncultured organism clone ELU0139T413-S-NIPCRAMgANa_000446 small subunit ribosomal RNĀ gene 94\%. The translation of the nucleotide sequence was more likely to be more accurate than just blastn search, because the protein sequences were more evolutionary and more conserved than nucleotides sequences.

The nucleotide sequences translated into protein using blastx database, showed that the result of the search contained same results from the Blastn search. The highest homology was two hypothetical protein HMPREF9553_00243 for [Escherichia coli MS 200-1], with an 87\% homology. The rest of the sequences gave two different strains of Escherichia coli (MS-198-1, 182-1, 187-1), as well as gave a high similarities to conserved hypothetical protein [Escherichia coli UTI89], Escherichia coli APEC O1 with 84\% identities (Jerome Boudeau, 1999; Vimlesh Yadav, 2009). The translation of the nucleotide sequence is more likely to be more accurate than just blastn search, because the protein sequences are more evolutionary and more conserved than nucleotides sequences (Wieds, 2007). This study evaluates the surface changes and effects on in vitro cell attachment and spreading brought about on prepared commercially pure titanium by multiple exposures to common sterilization methods. Information of contamination of cells is very relevant in pre-clinical in vitro cell cultures as a regulatory compliance for drug discovery high throughput screening (Eteme et al., 2015).
Mycoplasma contamination in mammalian cell cultures is often overlooked yet is a serious issue which can induce a myriad of cellular changes leading to false interpretation of experimental results (Ajibola et al., 2017). A simple and sensitive assay was used in this study to monitor mycoplasma contamination (mycosensor) based on degradation of the Gaussia luciferase reporter in the conditioned medium of cells. This assay proved to be more sensitive as compared to a commercially available bioluminescent assay in detecting mycoplasma contamination in seven different cell lines. The Gaussia luciferase mycosensor assay provides an easy tool to monitor mammalian cell contaminants in a high-throughput fashion (Awodiran et al., 2014). The electron microscopic examination of contaminated $\mathrm{C} 3 \mathrm{~A}$ cells was used to identify the presence of mico-organism TEM performed on cells monolayer. Bacterial was observed to adhere closely to $\mathrm{C} 3 \mathrm{~A}$ cells. The adhered bacteria strikingly induced the elongation of microvilli from the cell surface. At the site of close contact between the bacteria and the epithelial cell, the elongated microvilli surrounded the adherent bacteria

Cell culture is one of the most common methods used to recapitulate a human disease environment in a laboratory setting. Cell culture techniques are used to grow and maintain cells of various types including those derived from primary tissues, such as stem cells and cancer tumours (Kim 2007; Zenk and Hansel, 2009). However, a major confounding factor with cell culture is the use of serum and animal (xeno) products in the media. The addition of animal products introduces batch and lot variations that lead to experimental variability, confounds studies with therapeutic outcomes for cultured cells, and represents a major cost associated with cell culture. Here we report a commercially available serum-free, albumin-free, and xeno free (XF) media (Neuro-Pure(TM)) that is more cost-effective than other commercial media. Neuro-Pure was used to maintain and differentiate various cells of neuronal lineages, fibroblasts, as well as specific cancer 
cell lines; without the use of contaminants such serum, albumin, and animal products. Neuro-Pure allows for a controlled and reproducible cell culture environment that is applicable to translational medicine and general tissue culture.

\section{Conclusion}

Microbial contamination in cell and tissue culture is a constant problem, which can compromise development and applications of cell lines. This study showed a molecular approach in detecting the cell contaminant bacterial and gene sequence alignments. The closest phylogenetic relative was |HQ877772.1| Escherichia sp. A94 with 88\% $16 \mathrm{~S}$ ribosomal RNA gene sequence similarity. It was proposed that unidentified strain be assigned as type strain of species of the bacteria origin based on the 16S rRNA gene sequence search in Ribosomal Database project, small subunit rRNA and large subunit rRNA database together with the phylogenetic tree analysis. Bacterial species were shown to have at least one copy of the 16S rRNA gene containing highly conserved regions together with hyper variable regions. This study has also shown the important use of $16 \mathrm{~S}$ rRNA gene sequence to characterize the bacterial isolate from different cell lines. The Blastx database did confirm the nucleotide Blastn search result by suggesting that the unknown sequence belong to the bacteria group indicated very high homology with Escherichia coli.

The electron microscopic examination of contaminated $\mathrm{C} 3 \mathrm{~A}$ cells was used to identify the presence of micro-organism TEM performed on cells monolayer. Bacterial was observed to adhere closely to C3A cells. The adhered bacteria strikingly induced the elongation of microvilli from the cell surface. At the site of close contact between the bacteria and the epithelial cell, the elongated microvilli surrounded the adherent bacteria. In addition, dense area of staining, possibly related to an accumulation of cytoskeleton components were observed beneath the sites of intimate contact.

\section{COMPETING INTERESTS}

The authors declare that they have no competing interests.

\section{AUTHORS CONTRIBUTIONS}

CFN, ETF, SB contributed in the conception of the protocol, laboratory analysis and statistics, JF, GL, FAK, BN and DG, participated in manuscript writing and data mining. PT the principal investigator and project sponsor. All the authors participated in the review of the manuscript.

\section{ACKNOWLEDGEMENTS}

The authors thank the Centre for Biopolymer and Bio-molecular Research, Athlone Institute of Technology, Republic of Ireland for the funding of this work, and travel grants to visiting lecturer.

\section{REFERENCES}

Akanbi II AA, Kareem T, Adedoja A, Nyamngee A, Muhammed MBU, Abdulkareem K, Atata RF. 2017. Bacterial contamination of medical doctors' white coats as contributing factor to hospital acquired infections. Int. J. Biol. Chem. Sci., 11(1): 185-194.

Awodiran MO, Majolagbe FA, Komolafe OO, Adewumi AA, Oyebola OO, Oyewole RO. 2014. Cytogenetic study and serum protein characterization of Clarias gariepinus (Burchell, 1822) and Heterobranchus bidorsalis in South Western Nigeria. Int. J. Biol. Chem. Sci., 8(6): 2371-2386.

Behrendorff JB, Vickers CE, Chrysanthopoulos P, Nielsen LK. 2013. 2,2-Diphenyl-1-picryhydrazyl as a screening tool for recombinant monoterpene biosynthesis. Microb. Cell. Fact., 23: 12:76.

Blazkova HKK, Moudry P, Frisan T, Hodny Z, Bartek J. 2009. Bacterial intoxication Evokes cellular senescence with 
persistent DNA damage and cytokine signaling. J Cell. Mol Med., 6(5): 16-27.

Borman AM, Palmer M, Johnson EM. 2013. Rapid methods for the extraction and archiving of molecular grade fungal genomic DNA. Methods Mol Biol., 968: 55-62.

Case Gould MJ. 1984. Endotoxin in Vertebrate Cell Culture: Its Measurement and significance in uses and standardization of vertebrate Cell lines. Tissue Culture, Association, Gaithersburg, MD., 31(3): 125-136.

Croxton AN, Wikfors GH, SchulterbrandtGragg RD. 2012. Immunomodulation in eastern oysters, Crassostrea virginica, exposed to a PAH-contaminated, microphytobenthic diatom. Aquat Toxicol., 15: 118-119.

Degeling MH, Maguire CA, Bovenberg MS, Tannous BA. 2012. Sensitive assay for mycoplasma detection in mammalian cell culture. Anal Chem., 84(9): 42274232.

Ecology CFM. 2011. The Ribosomal Database Project (RDP). M. S. University. Michigan, Michigan State University Board of Trustees, $76 \mathrm{p}$.

Enow-Tanjong P, Teyim P, Kamga HL, Neba ES, Nkuo-Akenji T. 2016. Seroprevalence of HIV and hepatitis viruses and their correlation with CD4 T-cell lymphocyte counts in pregnant women in the Buea Health District of Cameroon. Int. J. Biol. Chem. Sci., 10(1): 219-231.

Eteme LF, Fokunang CN, Tchuenguem FF, Nolna D, Boula A, Ndze NV. 2015. Epidémiologie moléculaire du rotavirus du groupe A associé aux gastroentérites chez les enfants de moins de 5 ans dans la ville de Yaoundé Cameroun. Int. J. Biol. Chem. Sci., 9(5): 2561-2573. DOI : http://dx.doi.org/10.4314/ijbcs.v9i5.25.

Everoad RC, Yoshida S, Tsuboi Y, Date Y, Kikuchi J, Moriya S. 2012.
Concentration of metabolites from lowdensity planktonic communities for environmental metabolomics using nuclear magnetic resonance spectroscopy. J Vis Exp., 7(62): e3163.

Fogh J, Holmgren NB, Ludovici PP. 1971. A Review of Cell Culture Contaminations. In Vitro, 7(1): 26-41.

Garner CM, Chakraborti PR. 2000. Mycoplasmas detection in cell cultures: a comparison of four methods. Br. J. Biomed. Sci., 57: 295-301.

Grahn N, Olofsson M, Ellnebo-Svedlund K, Monstein HJ, Jonasson J. 2003. Identification of mixed bacterial DNA contamination in broad-range PCR amplification of $16 \mathrm{~S}$ rDNA V1 and V3 variable regions by pyrosequencing of cloned amplicons. Fed. Euro. Microbiol. Soc. Microbio. Letts., 219(2): 87-91.

Gupta PA, Ge X, Kostov Y, Rao G .2014. A completely noninvasive method of dissolved oxygen monitoring in disposable small-scale cell culture vessels based on diffusion through permeable vessel walls. Biotechnol Prog, 30(1):172-177.

Hay RJ. 1991. Operator-induced contamination in cell culture systems. Dev. Biol. Stand., 75(4): 193-204.

Ikonomi RJ. 2006. Cell biology: Laboratory Handbook, 1(3): 49-53. Incorporated C. 2002. Understanding and Managing Cell Culture Contamination. T. Bulletin. USA.

Jennifer P, Sue GMB, Jinnefer IF 2010. Got black swimming dots in your cells cultures? Identification of Achromobacter as a novel cell culture contamination. Biologicals, 32(2): 273277.

Jerome Boudeau AL, Masseret E, Bernard JA, Darfeuille-Michaud A. 1999. Expand+Infection and Immunityiai. 
asm.orgInfect. Immun., 67(3): 94499 944509.

Jimenez L, Ignar R, D'Alello R, Grech P. 2007. Use of PCR analysis for sterility testing in pharmaceutical environments. J. Rap.Methods. Automat. Microbiol., 8(85): 11-20.

Kim H. 2007. Ecological variables affecting predatory success in Myxococcus xanthus. Microb Ecol, 53: 571.

Klausegger A, Hell M, Berger A, Zinober K, Baier S, Jones S, Koffler B.1999. "Gram type-specific broad-range PCR amplification of rapid detection of 62 pathogenic bacteria. J. Clin. Microbiol., 37(5): 464-466.

Lleo MM, Bonato B, Tafi MC, Signoretto C, Pruzzo C, Canepari P. 2005. Molecular vs culture methods for detection of bacterial faecal indicators in groundwater for human use. Lett. App. Microbiol., 40(1): 289-294.

Mohammad-Qureshi SS, Haddad R, Palmer KS, Richardson JP, Gomez E, Pavitt GD. 2007. Purification of FLAG-tagged eukaryotic initiation factor 2B complexes, subcomplexes, and fragments from Saccharomyces cerevisiae. Methods Enzymol., 43(1): 113.

Nocker AC. 2008. Novel approaches toward preferential detection of viable cells using nucleic acid amplification techniques. Fed. Euro. Microbiol. Soc. Microbiol. Lett., 291(3): 137-142.
Testro AG. 2009. Toll-like receptors and their role in gastrointestinal disease. $J$ Gastroenterol Hepatol., 24(6): 943-954.

Thomas PC, Strotman LN, Theberge AB, Berthier E, O'Connell R, Loeb JM, Berry SM, Beebe D. 2013. Nucleic acid sample preparation using spontaneous biphasic plug flow. J. Anal Chem., 85(18): 86418646.

Uphoff CC, Horn GD. 2001. Prevention of mycoplasma contamination in leukemialymphoma cell lines. Human Cell., 14: 244-247.

Usta SN, Scharer CD, Xu J, Frey TK, Nash RJ.2014. Chemically defined serum-free and xeno-free media for multiple cell lineages. Ann Transl Med., 2(10): 97103.

Vimlesh YSP, Shipra IP, Srivastava PC, Praveen CV, Verma VG, Gupta VB, Anil KR. 2009. Identification of Comamonas species using 16S rRNA gene sequence. Bioinformation., 3(9): 381-383.

Wang Q, Garrity GM, Tiedje JM, Cole JR. 2007. Naïve Bayesian Classifier for Rapid Assignment of rRNA Sequences into the New Bacterial Taxonomy. Appl Environ Microbiol., 73(16): 5261-5267.

Zenk SF, Hensel M. 2009. Role of Salmonella enterica lipopolysaccharide in activation of dendritic cell functions and bacterial containment. J immunol. 183(4): 26972707. 